\title{
Role of Economic status and Mother's Work Status on Parenting
}

\author{
Priti Sharma ${ }^{1 *}$
}

\section{ABSTRACT}

Parenting is the process of promoting and supporting the physical, emotional, social and intellectual development of a child from infancy to adulthood. It refers to the aspects of raising a child aside from the biological relationship (Davies, 2000). Children are the building blocks of a developing family. Their level of development, socialization and advancement decide the future of any society or country, where parents play a key role in growing their children in a socially responsible person and righteous citizens (Steinberg, 2000). Parents fulfill the psychophysical needs of their children and help them growing physically, psychologically and spiritually under given norm of their community (Hoghughi, 1998). At the other end, children develop specific cognitive skills, learning strategies and personality attributes under the guidance of their parents. Simultaneously, their health problems, wellbeing needs and adaptive functioning are also dealt by their parents (Bradley and Caldwell, 1995). Parents encourage love, acceptance, warmth, independence and democratic ways of dealing with their children (Rohner, 1986). In many traditional societies like India, they appear to be made for the promotion of their children in their personal lives as well. Therefore, parenting is one of the most important functions of the institution of family of any society.

Keywords: Work status, Economic status, Positive parenting and Negative parenting.

Good parenting is the predictor of children's social and emotional adjustment (Maccoby 2000). In this concern, Martha Farah's PhD (2008) through the American Association for the Advancement of Science, reported that children who suffer deprivation in early life due to poor parenting and un-stimulating home lives show altered patterns of brain growth by the time they are aged 15 (Rao \& Betancourt, et al. 2010). The empirical researches have evident that children are influenced by the way parents behave towards them (Kiff, Lengua, \& Zalewski, 2011).The inability to deal with child's communications and emotional needs contributes further to the child's disturbance in behavior and personality as well as total development. This is the reason that unsupportive parenting, even due to genuine reason is psychologically harmful for the children, affecting their adjustment capabilities (Maccoby 2000; McLeod et al. 2007). Therefore,

\footnotetext{
${ }^{1}$ Research Scholar, Department of Psychology, C.C.S. University Campus Meerut, India *Responding Author

(C) 2016 I P Sharma; licensee IJIP. This is an Open Access Research distributed under the terms of the Creative Commons Attribution License (http://creativecommons.org/licenses/by/2.0), which permits unrestricted use, distribution, and reproduction in any Medium, provided the original work is properly cited.
} 


\section{Role of Economic status and Mother's Work Status on Parenting}

proper upbringing of a child by an aware an educated parent is necessary for realistic attitude towards self, family and society, which may be of any social class, creed or status.

Types of Parenting: Psychologists have divided parenting in two different roles. They are fathering and mothering, which are complementary to each other for the child. Though the two concepts were critical to a group of social psychologists but every society deals with different defined roles of each other. Fathering refers to a relationship that represents power, financial security, dominance, and connectedness, at the same time, the child incurs abilities, material, spiritual values etc from their father. The mothering was defined as an intimate emotional interaction between mother and her child which determines proper development and socialization process of child. Although, American Psychological Association (2005) has long declared that the word mothering should generally be avoided, because it is a biologically based pattern of behavior that includes breastfeeding, carrying, secure attachment, mutual rewards, enjoyment and empathy..........which help to sustain healthy development if the environment is supportive and meets basic human needs (Cook, 2009). This paper is considering parenting as mothering.

Functionally, parenting was also divided into two other types they were negative and positive parenting. Negative parenting refers to negative emotional attitudes towards children which encourage hate, discouragement, rejection, conservatism, autocratism, dependency, and submission. Negative parental discipline is associated with increased risk of conduct problems (Hill, 2002). Positive parenting refers to parental behaviors based on the best interests of the child. It provides nurturing, empowering, recognition and guidance, and involves setting boundaries to enable the full development of the child. Positive parenting supposes respect for children's rights and a nonviolent environment where parents do not use corporal or psychologically demeaning punishment to resolve conflict or teach discipline and respect (Council of Europe, 2012). Such a parenting is instrumental to early child development with lasting effects on a child's overall health, social relationships, language development and academic achievement (Piotr Wilk, 2006; Landy \& Tarn, 1996, 1998)

Parenting and Economic Status: Empirical studies have revealed that ways of parenting and parenting attitude differ in different economic status families, as this variable functions as a facilitator in the process of parenting. This is because the parents belonging to rich family have different attitude and ways of dealing with their children then the parents belonging to medium or lower economic status family. Besides it, the children belonging to poor or higher economic status groups limit with one or the other parenting role/expectations due to demanding personal, professional or business needs of their parents where as the children from medium socio-economic status group become beneficiating of parenting and nurturance by their mother and father both (Kim and McKenry ,1998, McDermott, 2001). 


\section{Role of Economic status and Mother's Work Status on Parenting}

It is observed in the families with high economic status, that father is busy in their profession/job/business activities and mother has other affairs to fulfill her subjective needs and both more often fail to give proper guidance, value, times, care and raring to their children. They can arrange better facilities and money to fulfill other demands of children but the child is left unattended at need, consequently suffer from emotional dissatisfaction. The children of this chunk of population may be more overt, expressive and independent, but always prone to be involved in antisocial or criminal activities (Elder, \& Caspi, 1988). Whereas, the parents of medium economic status families have realistic views about parenting due to sufficient resource availability, awareness about parents-child relationship and proper interaction with child. They may use physical punishment for discipline but simultaneously care for child's needs at hand. Due to neighborhood competition they encourage educational and career activities more efficiently and able to give needful environment to their children too (Baldwin \& Cole, 1990). The parents belonging to lower economic status have instability and scarcity of economic conditions which bring more psychological distress and hostility in parenting behavior (Leder \& Caspi, 1988). Consequently, they are not able to provide required facilities and implant unobserved psychological distress in their children, which left the child with guilt and inferiority as well as suppressed aggression against parents and society. Parents of this group would more likely to use physical punishment for discipline and would be less supportive or affectionate with their children due to individual distress (Gecas, 1979; McLoyd, 1990). Therefore, the economic status is an important variable to be studied in relation to parenting behavior in Indian context.

Parenting and Mother's Work Status :Though, the surveys of NDTV, India Today and The Guardian revealed that India is the most dangerous place for women but in last four decades of Indian socioeconomic development, a major shift has been seen in the social conditions, living standard and life style of Indian women (mother). Today, the females over 25 years of age with secondary education are 26.6\%, women in labor force are 32.8\% (Human Development Report. 2010 and 2009 respectively) and the senior positions in businesses have catapulted from 9\% in 2011 to 14\% in 2012 (International Business Report, IBR' by Grant Thornton) and so on (Wikipedia). The women of present India is no more a traditional home bound charlady, rather they have developed the abilities of bearing dual roles of her family as a wife and employee in the office expeditiously. They are educated and aware thus tend to experience changes more efficiently and empowering their abilities to adopt the changing socioeconomic environment in all conditions but at the same time some area has emerged as weak outcomes of this social change that is altered psychological and emotional development of their children.

About two decades before, it was observed by researchers in India that working women are not able to nurture their children properly thus affecting emotional development of their children (Dunifon, Kalil \& Bajracharya, 2005; Knaub, Eversol, \& Voss, 1983; Nettelbladt, Uddenberg \& Englesson, 1981). Previously it was held that fulltime working women would serve her office and family efficiently but unable to devote needful time even for her, then how could she 


\section{Role of Economic status and Mother's Work Status on Parenting}

commit valuable time to their children at need. Consequently, this would give rise to isolation, discouragement, inattention, miscommunication, aggression and behavior problems in her children (Chamberlain \& Patterson, 1995; Hill et al. 2003). But the studies done in the current scenario indicated a significant shift in traditional view about working mother to the fact that they executes more successful parenting with higher sensitivity then a home maker mother (Brooks-Gunn et al., 2010). Because being more educated and aware, she is exposed to variety of information around her, thus she bears a responsible parenting (Horwood and Fergusson, 1999). Her advanced thinking about parenting style, economic stability and high confidence help her to nurture her child with love, care, and respect. In such conditions the child probably develops with self confidence and an independent attitude. Against this the house maker women were explained to be poorly informed about needs of modern world and half filled information about new changes and stagnant to old values lead them to have contradictory expectations from their children, thus make their children problematic, aggressive, argumentative and violent. A house maker woman can care the child at home and satisfy emotional needs but equally pressurize their children to live their life according to her own wish (as she has learnt the same during her own socialization at childhood) which influence the socioemotional development of the child. They are also observed to devote less time in school related activities of their children then working mothers (Muller, 1995). Therefore work status of mother was another important variable considered in the study to find out casual relationship with parenting behavior. Considering above discussion in mind the present study aimed to find out the effect of economic status on parenting of working and house maker middle age adult mothers.

\section{METHOD}

\section{Sample:}

The sample for the study was consisted of 120 working and home maker mothers of age range 3040 years. The sample was taken through quota random sampling from Hapur City. Only those subjects were included in the study whose husband was working in Govt. or Private sector. These subjects were consisted of three groups of Economic Status, i.e., high (HES) medium (MES) and low (LES)] with $40 \mathrm{Ss}$ in each group and each economic status group was further consisted of two groups of Mother's Work Status, they were working and house maker mothers with 20 subjects in each cell. In this way a $3 \times 2$ factorial experimental design was employed in the research.

\section{Tools:}

In the present study following scale were used for data collection:

1. Case Record Sheet: It was consisted of general information about child for the purpose of selection of subjects; they were name, age, gender, parental occupation, education etc.

2. Multi Dimension Parenting Scale: The scale was developed by Chauhan, N.S. and Khokhar, C.P. (1985). The scale is consisted of 56 items used to measure level of parenting. This scale measures the level of parenting on 7 opposite paired dimensions. They 
are Love-Hate, Encouragement-Discouragement. Acceptance-Rejection, ProgressivenessConservatism, Democratism - Autocratism, Independency-Dependency, and DominanceSubmission. The scale has a high average test-retest reliability of 0.62 and split-half reliability of 0.70 . The obtained average validity of the tool was 0.70 on positive \& negative dimension on the basis of score obtained from 50 parents.

\section{RESULTS}

The data was systematically tabulated and statistically analyzed by mean, S.D. and Analysis of Variance. Obtained results and its detailed interpretation and discussion are given as follows:

1 Economic Status and Positive Parenting: The result Table-1 showing summary of ANOVA for positive parenting scores indicated that the economic status significantly influenced positive parenting of mothers $[\mathrm{E}(92, \mathrm{l} 14)=39.35 ; \mathrm{p}<0.01]$. This means that three groups of economic status differ significantly in positive parenting. The mean and S.D. scores of positive parenting of three economic groups indicated that MES group (Mean-162.51 SD-14.96) was bearing significantly better positive parenting than HES (Mean-133.65, SD- 17.92) and LES (Mean- 135.14, SD18.27).

Table 1: Mean S.D. and F-scores for Positive Parenting of Three Groups of Economic Status and two Groups of Mother's Work Status.

\begin{tabular}{|l|l|l|l|l|}
\hline Variable & $\begin{array}{l}\text { Level of } \\
\text { variance }\end{array}$ & Mean & S.D. & F-Score \\
\hline \multirow{2}{*}{$\begin{array}{l}\text { Economic Status } \\
\text { Status (ES) }\end{array}$} & High & 133.65 & 17.92 & \multirow{3}{*}{$39.35^{* *}(2)$} \\
\cline { 2 - 4 } & Medium & 162.51 & 14.96 & \\
\cline { 2 - 4 } $\begin{array}{l}\text { Work Status } \\
\text { (WS) }\end{array}$ & Working & 135.14 & $18 \mathrm{f} 27$ & \multirow{2}{*}{$9.73^{* *}(1)$} \\
\cline { 2 - 4 } & House Maker & 148.43 & 21.35 & \\
\hline
\end{tabular}

Work Status and Positive Parenting : Table- 1 also indicated that the mothers work status was also found significantly effective on positive parenting at 0.01 level of significance $[F(1,114)=9.73$; $\mathrm{p}<0.01]$. This means that mother's occupation significantly influenced positive parenting of mothers. The mean and SD scores from Table -1 depicted that working mothers [Mean-148.43, S.D.-21.35) were significantly higher in positive parenting than house maker mothers (Mean135.10, SD- 20.94). This indicated that positive parenting of working mother was significantly better than house maker mothers.

Economic Status and Negative Parenting : The table-2 is showing summary of analysis of variance for negative parenting. The table depicts that the economic status was found significantly effective on parenting of mother's at.05 level of significance $[\mathrm{F}-(2,114)=4.48, \mathrm{p}<.05]$. This means that the three groups of economic status differ significantly in negative parenting of working and house maker mothers too. Further the table- 2 is showing that the mean and SD scores

(C) The International Journal of Indian Psychology, ISSN 2348-5396 (e)| ISSN: 2349-3429 (p) | 66 
of negative parenting of MES (M-67.67, SD-16.88) group was significantly higher as compared to LES (M-60.66, SD-19.27) and HES (M-55.93 SD-14.94). This means that mothers MES group express higher negative parenting then other two groups.

Table -2: Mean and S.D. Scores of Negative Parenting of the Groups of Economic Status and Mother's Work Status.

\begin{tabular}{|c|c|c|c|c|}
\hline Variables & Level of Variable & Mean & S.D. & F-Score (df) \\
\hline \multirow{3}{*}{$\begin{array}{l}\text { Economic Status } \\
\text { (ES) }\end{array}$} & High & 55.93 & 14.94 & \multirow{3}{*}{$\begin{array}{c}4.84^{* *} \\
(2)\end{array}$} \\
\hline & Medium & 67.67 & 16.88 & \\
\hline & Low & 60.66 & 19.27 & \\
\hline $\begin{array}{ll}\text { Work } & \text { Status }\end{array}$ & Working & 60.63 & 18.30 & \multirow{2}{*}{$\begin{array}{l}26 \\
(1)\end{array}$} \\
\hline (WS) & House Maker & 62.21 & 17.12 & \\
\hline
\end{tabular}

Work Status and Negative Parenting: From table 2 it can also be seen that mothers work status was not found to significantly effective on negative parenting of mothers at .05 of significance [F$(1,114)=0.26, p>05]$. This means that the negative parenting did not differ significantly in between groups of work status. The study of same table- 2 also indicated that mean negative parenting score for house maker mothers (M-62-21, SD-17.12) which was slightly higher than working mothers (M-60.63, SD-18.30) but the two groups did not differ significantly in negative parenting.

\section{DISCUSSION}

The present study aimed to investigate the effect of economic status and work status on positive and negative parenting of middle age adult mothers. The study was conducted on 120 mothers of three economic status of working and house makers. The detailed interpretation of results indicated that economic status was found to be significantly effective variable on positive and negative parenting of working and house maker mothers. The results also co-vary with the researches of Spencer and Dornbusch 1990) who suggested that SES significantly influence parenting due to depression and current opportunities. This is also observed that the socioeconomic issue has effects on family factors, which in turn influence parenting behavior and consequently result in differed child's attitude and behavior (Dodge, et al., 1994; Larzelere and Patterson, 1990; Stern and Smith, 1995). Further the result indicated that the mothers of MES group have more interactive relationship with their children as compared to other two economic status groups, i.e., HES and LES. The reason may lie in the fact that mothers of LES and-HES have so many psychological factors which divert their attention against their children, therefore, they show poor parental supervision, vigilance and child rearing (Farington and Loeber, 1999; Smith and Stern, 1997). 


\section{Role of Economic status and Mother's Work Status on Parenting}

In Indian society, the mothers of LES share their husband's business of earning bread for family and children. They have poor management skills thus do not encourage proper care, love, and satisfactory emotional needs of their children at need Smith and Stern (1997). They always bear mental pressures of instable economic conditions and impose similar distress over their children in the form aggression and guilt, thus show poor parenting. They use punishment and negative rewards for controlling children (Gecas, 1979; McLoyd, 1990). On the other hands HES are being more materialistic fulfill so many monetary needs and provide best physical world facilities but not able to give value time to their children thus children of this group experience deprivation of love, attention and care and consequently feel insecure, frustrated, isolated and rejected by family and society. These children develop hate and aggression towards their parents and become prone to involve in criminal activities too (Lipsey and Derzon, 1998). Therefore, both groups have scored poorly on positive or negative parenting as compared to MES.

When it comes to MES it can be seen that at least in Indian society husbands of MES group are hard worker, show devotion to family and feel worthy of saving time for their family and children. The husbands share family responsibilities like, house making, marketing, and school liabilities irrespective of their wives working or house making status. Thus children of this group get quality time, proper love, encouragement and independence from their mother as compared to other two groups thus never fall in negative or anti-social activities (Kolvin, et al., 1988a). Unfortunately in many cases children vary over personality, attitude and mood thus more often mother's exaggerated interaction result in negative parenting attitudes and attributes too (Farington and Loeber, 1999). That is why mothers of MES have also scored higher on negative and positive parenting both as compared to other two, LES and HES groups of middle age adult mothers.

Further the study revealed that working mothers were found to be scored significantly higher on positive parenting as compared to house maker mothers. This means that working mothers give positive parenting more efficiently than house makers. The positive parenting particularly warmth (Masten and Coatsworth, 1998), serve the child to protect him/her from the detrimental influence of negative parental practices. The working mothers of $80 \mathrm{~s}$ might be failing to give better parenting to their children as compared to house maker mothers due to inability to give quality time to their children and dependence of women on husband and family. But in the present time working mothers are economically independent and mentally realistic about the things around them, thus they can understand their child's needs better and resolve them easily. They know the challenges of present conditions, and what course of action to be taken for the development of her children. This the reason that she succeeds in providing satisfaction and emotional help at hand to her children and child feels loved, encouraged, accepted, independent and progressed under her parenting and child experience fewer behavior problems (Kotchick and Forehand 2002). Where as a house maker satisfy one's child needs emotionally and feel helpless 


\section{Role of Economic status and Mother's Work Status on Parenting}

when child start argument about new challenges and emerging needs at hand thus fail to provide good mothering to her child. She may impose one's own childhood experiences over her child and suppress the natural desires and instincts of child, but, during the course she becomes the victim of her child's emotional insecurity and mental stress. Thus, under her parenting the child feels hated, discouragement, rejected, conservative and dependent of mothers which are the dimensions of negative parenting. This was the reason that working mothers were found to be bearing good parenting.

As far as negative parenting is concerned physical punishment, negative leveling (idiot, moron, dirty etc.), and mental pressure for high academic achievement is very common practice in almost all Indian, families. This cause frustration, antisocial behavior, feeling of rejection, violence and offence in children (Herrenkohl, et al 2000; Kelly, et al., 1992; Farington, Loeber and stquthaner-Loeber, 2003) that results in negative parenting. Therefore no significant effect of work status was observed on negative parenting of mothers.

\section{Acknowledgments}

The author appreciates all those who participated in the study and helped to facilitate the research process.

\section{Conflict of Interests}

The author declared no conflict of interests.

\section{REFERENCES}

Baldwin, A.L., Baldwin, C.\& Cole, R.E. (1990). Stress-resistant families and stress resistant children. In J. Rolf, A.S. Masten, D. Sicchetti. K.H. Nuechterlein, S. Weintraub (Eds.) Risk and protective factors in the development of psychopathology (pp. 257-280). New York: Cambridge University Press.

Bradley, R. H., \& Caldwell, B. M. (1995). Caregiving and the regulation of child growth and development: Describing proximal aspects of care giving systems. Developmental Review, 15, 38-85.

Brooks-Gunn, J., Han. W., \& Waldfogel, J. (2010). First-year maternal employment and child development in the first 7 years: What distinguishes women who work full-time, part-time, or not at all in the 1st year? Monographs of the Society for Research in Child Development, 75, 35-49.

Chamberlain, P., \& Patterson, G. (1995). Discipline and child compliance in parenting. In M. Bornstein (Ed.), Handbook of parenting, Vol. 4: Applied and practical parenting (pp. 205225). NJ: Erlbaum.

Chauhan, N.S. \& Khokhar, C.P. (1985) Multi dimensional parenting scale. Published in 2010 by National Psychological Corporation, Agra India

Cook, P.S. (2009). Mothering Denied. The book retrived on 17March, 2012 from: www. members.

(c) The International Journal of Indian Psychology, ISSN 2348-5396 (e)| ISSN: 2349-3429 (p) | 69 


\section{Role of Economic status and Mother's Work Status on Parenting}

optusnet.com.au/pcook62/090424MDA4.pdf, pp-10 Human Development Report; Sustainability and Equity". United Nations Development Programme. 2011. p. 139. Site: http://hdr.undp.org/en/media/HDR2011 EN Complete.pdf.

Council of Europe (2012). Positive Parenting: What is it. Retrieved on June, 2012 fromhttp://www.coe.int/ t/dg3 children/ corporal punishment/ positive\%20 parenting/defaulten.asp

Davies, Martin (2000). The Blackwell encyclopedia of social work. Wiley-Blackwell. p. 245.ISBN 978-0-631 -21451-9.

Dodge, K.A., Pettit,G.S., \& Bates, J.E. (1994). Socialization mediators of the ralition between socio-economic status and child conduct problems. Child Development, 65,649-665.

Dunifon, R., Kalil, A. \& Bajracharya, A. (2005). Maternal working conditions and child well-being in welfare-leaving families. Dev Psychol., 41(6):85l-9.

Elder, G.H. \& Caspi, A. (i 988). Economic stress in lives: Developmental perspective. Journal of Social Issue, 4, 25-45.

Farrington, D.P. \& Loeber, R. (1999). Transatlantic replicability of risk factors in the development of delinquency. In P. Cohen, C. Slomkowski \& L.N. Robins (eds.), Historical geographical influence on psychopathology. pp. 299-329), Mahwah, NJ: fcawremce Erlbaum.

Farrington, D.P., Loeber, R. \& Stouthamert-Loeber, M. (2003). How can the relationship between race and violence be explained? In D.F. Howkins (Ed.), Violent crime: Assessing race and ethnic differences (pp. 214-237). Cambridge University Press

Free Press. Herrenkohl, T.I., Maguin, E., Hill, K.G.. Hawkins, J.D., Abbott, R.D. \& Catalano, R.F. (2000). Developmental risk factors for youth violence. Journal of Adolescent Health, 26, 176-186.

Gecas, V. (1979). The influence of social class on socialization. In W. Burr,R. Hill, F. Nye \& 1. Reiss (Eds), Contemporary theories about the families: Research based theories (Vol. I, pp. 356-404). New York:

Hill, J. (2002). Biological, psychological and social processes in the conduct Hill, N.E., Bush, K.R., \& Roosa, M.W. (2003). Parenting and family socialization strategies and children's mental health: Low-income, Mexican-American and Euro-American mothers and children. Child Development, 74, 189-204.

Hoghughi, M. (1998). The importance of parenting in child health. British Medical Journal, 316: $1545-1550$.

Horwood, L. J., \& Fergusson, D. M. (1999). A longitudinal study of maternal labour force participation and child academic achievement. Journal of Child Psychology and Psychiatry, 40, 1013-1024. doi: $10.1111 / 1469-7610.00520$

Kelley, M.L., Power, T.G. \& Wibbush, D.D. (1992). Determinant of disciplinary practices in low income black mothers. Child Development, 63, 573-582

Kiff, C.J., Lengua, L.J. \& Zalewski, M. (2011). Nature and nurturing: parenting in the context of child temperament. Clin Child Fam Psychol Review, 14(3):25l-301. 


\section{Role of Economic status and Mother's Work Status on Parenting}

Kim, H. K., \& McKenry, P. C. (1998). Social networks and support: A comparison of African Americans, Asian Americans, Caucasians, and Hispanics. Journal of Comparative Family Studies, 29, 313-334.

Knaub, P. K., Eversol, D. B., \& Voss, D. H. Is parenthood a desirable adult role? An assessment of attitudes held by contemporary women. Sex Roles, 9, 459-465.

Kolvin, L, Miller, F.J.W.. Fleeting, M., \& Kolvin, P.A. (1988a). Risk/protective factors for offending particular reference to deprivation. In M. Rutter (Ed.), Studies of psychos octal risk. The power of longitudinal data (pp.77-95). Cambrigde, U.K: Cambridge University Press.

Kotchick, B. A., \& Forehand, R. (2002). Putting parenting in perspective: A discussion of the contextual factors that shape parenting practices. Journal of Child and Family Studies, 11, 255-269.

Landy, S. and Tarn, K..K. (1996). Yes, parenting does make a difference to the development of children in Canada. In Growing Up in Canada, National Longitudinal Survey of Children and Youth; pp. 103-118. Ottawa: Human Resources Development Canada and Statistics Canada.

Landy, S. and Tarn, K..K. (1998). Understanding the contribution of multiple risk factors on child development at various ages. Working Paper W-98-22E. Ottawa: Human Resource Development Canada.

Larzelere, R..E., \& Patterson, G.R. (1990). Parental management: Mediator of the effect of the socio-economic status on delinquency. Criminology, 28,301-324.

Leder, G.H. \& Caspi, A. (1988). Economic stress in lives: Developmental perspective. Journal of Social Issue, 4, 25-45.

Lipsey, M.W. \& Derzon, J.h. (1998). Predictor ofviolet or serious delinquency in adolescence ad early adulthood: Asynthesis of longitudinal research. In R. Loeber \& D.P. Farrington (Eds.), Serious and violet juvenile offenders: Risk factors and successful interventions (pp.86-105). Thousand Oaks,C.A: Sage.

Maccoby, E. (2000). Parenting and its effects on children: On reading and misreading behavior genetics. Annual Reviews of Psychology, 51, 1-27.

Masten, A. S., \& Coatsworth, J. D. (1998). The development of competence in favorable and unfavorable environments: Lessons from research on successful children. American Psychologist, 53, 205-220.

McDermott, D. (2001). Parenting and ethnicity. In M. J. Fine \& S. W. Lee (Eds.), Handbook of diversity in parenting education: The changing faces of parenting and parent education (pp. 73-96). San Diego, CA: Academic Press, Inc.

McLeod, D., Weisz, J. R., \& Wood, J. J. (2007). Examining the association between parenting and childhood depression: A meta-analysis. Clinical Psychology Review, 27, 986-1003.

McLoyd, V.C. (1990). The impact of economic hardship on black families and children: Psychological distress, parenting, and socio-emotional development. Child development, 


\section{Role of Economic status and Mother's Work Status on Parenting}

61,311-346.

Muller, C. (1995). Maternal employment, parental involvement, and mathematics achievement among adolescents. Journal of Marriage and Family, 57, 85-100. doi: $10.2307 / 353818$

Nettelbladt , P., Uddenberg, N. \& Englesson, I. (1981). Sex-role patterns, paternal rearing attitudes and child development in different social classes. Acta Psychiatr Scand, 64( 1): 12-24.

Piotr Wilk (2006). Positive parenting in london \& middlesex county. The Health Index: Tracking Public Health Trends in London \& Middlesex County, 8. Retrieved on June, $2012 \quad$ from http://www.healthunit.com/articlesPDF/12193.pdf

Rao, H., Betancourt, L.M., Giannetta, J.M., Brodsky, N.L., Korczykowski, M., Avants, B.B., Gee. J.C., Wang, J.J., Hurt, H., Detre, J.A., Farah, M.J. (2010). Early parental care is important for hyppocampal maturation: Evidene from biain morphology in humans. Neuro-image,49, 1144-1150.

Rohner, R. P. (1986). The warmth dimension: Foundations of parental acceptance-rejection theory. Beverly Hills, CA: Sage.

Smith, CA. \& Stern, S.B. (1997). Delinquency and antisocial behaviour: A review of family processes and intervention research. Social Service Review, 71,382-420.

Spencer, M. and Dornbusch, S. (1990). Ethnicity and adolescence. In S. Feldman \& G. Elliot (Eds.), At the threshold: The developing adolescent. Cambridge, M.A.: Harward University Press.

Steinberg, L. (2000). We know some things: Parent-adolescent relations in retrospect and prospect. Presidential address presented at the biennial meeting of the Society for Research on Adolescence, Chicago, IL.

Stern, S.B. \& Smith, C.A.(1995). Family processes and delinquency in an ecological context. Social Service Review, 69, 705-731.

WHO (2005). European strategy for child and adolescent health and development. Retrieved on June, 2012 from WHO/Europe web site at http://www.euro.who. int/pubrequest.

How to cite this article: P Sharma (2016), Role of Economic status and Mother's Work Status on Parenting, International Journal of Indian Psychology, Volume 3, Issue 4, No. 58, ISSN 23485396 (e), ISSN: 2349-3429 (p), DIP: 18.01.045/20160304, ISBN: 978-1-365-24976-1 